\title{
Mevsimlik Tarım İşçisi Kadınlarda Doğurganlık ve Aile Planlaması Yöntemi Kullanım Durumlarının Belirlenmesi
}

\author{
Determination of Fertility State and Use of Family Planning Method in Female Seasonal \\ Agricultural Workers
}

\author{
Şemsinnur GÖÇER, Mustafa Mümtaz MAZICIOĞLU, Rabiye Özlem ULUTABANCA, Demet ÜNALAN, Muhsin \\ KARADUMAN, Kübra ŞAHIN TARHAN
}

ÖZ

Amaç: $\mathrm{Bu}$ çalışmada, mevsimlik tarım işçisi kadınlarda doğurganlık ve aile planlaması yöntemi kullanım durumlarının belirlenmesi amaçlanmıştır.

Gereç ve Yöntem: Kesitsel tipteki bu çalışma; Temmuz-Kasım 2016 tarihleri arasında Kayseri ve çevresinde tarım işçiliğinde çalışmak amacıyla gelen ve çeşitli kamp alanlarında bahar, yaz ve güz mevsimi boyunca sürekli yer değiştiren mevsimlik tarım işçileri üzerinde yapıldı. Veri toplama aracı olarak kadınların yaş, cinsiyet, medeni durum, öğrenim durumu vb. sosyodemografik özellikleri ile canlı doğum, ölü doğum, düşük, yaşayan çocuk sayısı gibi doğurganlık özelliklerini ve aile planlaması yöntemi kullanım durumlarını belirlemeye yönelik 45 soruluk anket formu kullanıldı. Veriler, araştırma ekibindeki 4 araştırmacı tarafından tarım işçilerinin çadır kurdukları bölgelerde yüz yüze görüşme yöntemiyle toplandı. Bu çalışmada 141 evli kadına ait veriler değerlendirildi.

Bulgular: Araştırma grubunun yaş ortalaması $34.2 \pm 12.1 \% 0.7$ 'si 18 yaş altında, \%69.5'i okuryazar değildi. Evli kadınların \% 50.3'ünün ilk gebelik yaşı 15-20 arasındaydı. Canlı doğum sayısı 4 'ten fazla olan kadınların oranı \% 62.7 idi. En az bir kez düşük yapmış kadınların oranı $\% 42.5$ iki gebelik arasında geçen süre 2 yıldan az olan kadınların oranı ise \%86.5 idi. Kadınların \% 70.6'sının bugüne kadar hiç aile planlaması yöntemi kullanmadığı belirlendi. Sonuç: Tarım işçisi kadınların genel topluma göre erken çocuk sahibi olduğu, çok sayıda ve sık aralıklarla gebe kaldığı, ayrıca doğum kontrol yöntemi kullanım oranının oldukça düşük düzeyde olduğu belirlendi.

Anahtar Kelimeler: Mevsimlik tarım işçisi, kadın, üreme sağlı̆̆ aile planlamas 1

\begin{abstract}
Objective: In this study, it was aimed to determine the fertility status and the use of family planning method in female seasonal agricultural workers.

Materials and methods: This cross-sectional study was carried out on seasonal agricultural workers who came to work in Kayseri and the surrounding areas between July and November 2016 and resided in different camping sites during the spring, summer and autumn. A 45-items questionnaire including questions labor age, gender and marital status was used to determine the sociodemographic characteristics and the fertility characteristics such as live birth, stillbirth, low, number of living children, and the use of family planning method. Data were collected by face-to-face interviews by 4 researchers at camping sites. We evaluated data from 141 married women.

Findings: Mean age was $34.2 \pm 12.1$. Of subjects included, $55.1 \%$ was female, $50.3 \%$ were married, and $69.5 \%$ were illiterate. Of married women, $5.0 \%$ of were under the age of 18 and age at first pregnancy was 15-20 years. The rates of women with at least one abortion and those with less than 2 years between 2 births were $42.5 \%$ and $86.5 \%$, respectively. The rate of women with more than 4 live births was $62.7 \%$. It was determined that no family planning method was used in $70.6 \%$ of the women.

Conclusion: It was found that women who are agricultural workers had child at younger age, higher number of pregnancy, more frequent pregnancy than general population with extremely low rates of use of contraceptive methods.
\end{abstract}

Keywords: Seasonal agricultural worker, woman, reproductive health, family planning

\section{GíRIS}

Tarım işçileri "sürekli, mevsimlik ve geçici tarım işlerinde ücret karşıllı̆ 1 bir hizmetle istihdam edilen kişiler" olarak tanımlanmaktadır (1). Mevsimlik tarım işçileri, dünyada var olan 1.1 milyar tarım işgücünün yaklaşık 450 milyonunu
Şemsinnur GÖÇER (四), Mustafa Mümtaz MAZICIOĞLU, Rabiye Özlem ULUTABANCA, Demet ÜNALAN, Muhsin KARADUMAN, Kübra ŞAHIN TARHAN

Erciyes Üniversitesi Tip Fakültesi Halk Sağllğl Anabilim Dalı-KAYSERI e-posta: semsinnurgocer@gmail.com 
oluşturmaktadır (2). Tarım dünyada olduğu gibi ülkemizde de büyük öneme sahip olup \%21.1 ile ikinci en yüksek istidam alanıdır (2). Türkiye'de Türkiye İstatistik Kurumu (TÜIK) 2016 verilerine göre; istihdam edilen toplam nüfusun (26 milyon 275 bin) \%18.3'ü tarım sektöründe çalışmaktadır. Türkiye'deki tarım işgücünün de büyük kısmını mevsimlik tarım işçileri oluşturmaktadır (3). Genelde tarım işçileri, özelde mevsimlik tarım işçileri işin tabiatı gereği olarak iş güvenliği ve sağlıkları açısından risk altındadırlar (4). Geçici ya da gezici tarım işçilerinin günlük yaşamlarında; taşıma, barınma, sosyal güvenlik, eğitim, sağlık, beslenme, temizlik gibi pek çok konuda oldukça zorluk çektikleri bilinmektedir (5). Mevsimlik tarım işçilerinin çalışma koşullarının, ücret, konut ve beslenme olanaklarının oldukça yetersiz olduğu görülmektedir. $\mathrm{Bu}$ yetersizlik işçilerin sosyo-ekonomik yaşamları ve sağlıklarını da olumsuz yönde etkilemektedir $(6,7)$.

Kadınlar; tarımsal işlerde üreten, değerlendiren, pazarlayan ve ev içi rolleri açısından önemli bir konuma sahiptir. Gezici veya geçici konumda çalışan kadın tarım işçileri tarımsal uğraşılarının yanı sıra, ev içi rolleri açısından da ağır bir sorumluluk altındadır. Bir yandan ailenin günlük yaşam gereksinimlerini yerine getirmeye çalışan bu kadın işçiler, bir yandan da aile ekonomisine katkıda bulunmak amacıyla çalışmaktadır $(8,9)$. Kadın tarım işçileri ilkel barınma koşullarında tarım işçiliği yanında; yemek hazırlama, bulaşık ve çamaşır yıkama, çocuk bakımı ve su temini gibi birçok görevi de yürütmektedirler. Diğer taraftan bu gruba yönelik sağlık hizmetlerinin temininde bu işçilerin bilgi ve tutumları dışında özellikle ulaşımda da aksaklıklar yaşanmaktadır (10,11). Yetersiz koşullar nedeniyle bozuk hijyen, düşük sosyo-ekonomik düzey, genç yaşta evlenme ve beraberinde adölesan ya da erken yaşta gebelikler, çok sayıda ve sık aralıklarla gebelik ve doğum, tarım alanlarında doğum öncesi, sırası ve sonrası sağlık hizmetine erişememe annenin ve bebeğin sağlık risklerini artırmakta hatta bebek ve anne ölümlerine neden olabilmektedir (9-12).

Bu çalışmada, Kayseri İl merkezine 30 dakika ile bir saat mesafede ancak şehirden neredeyse tamamen izole çalışan ve konaklayan gezici mevsimlik tarım işçisi kadınların (MeTIKK) doğurganlık özelliklerinin ve aile planlaması yöntemi kullanım durumlarının belirlenmesi amaçlanmıştır.

\section{YÖNTEM}

\section{Araştırmanın Tipi}

Mevsimlik tarım işçileri ile yapılan bu araştırma kesitsel tiptedir.

\section{Araştırmanın Yapıldığı Yer ve Zaman}

Bu çalışma; Temmuz-Kasım 2016 tarihleri arasında Kayseri ve çevresinde tarım işçiliğinde çalışmak amacıyla gelen ve çeşitli kamp alanlarında bahar, yaz ve güz mevsimi boyunca sürekli yer değiştiren mevsimlik tarım işçileri üzerinde yapildı.

\section{Araştırmanın Evreni}

Kayseri ve çevresine çalışmamızdan bir yıl öncesi yaklaşık 4000 tarım iş̧̧isinin geldiği bilgisi Kayseri Halk Sağlığ Müdürlüğü’nden alındı. Buna göre bu tarım işçilerinin en az \%10'una ulaşılması (400 tarım işçisi) hedeflendi. Tarım işçilerinde ele alınan değişkenlerin çok farklı çok sayıda olması nedeniyle herhangi bir değişken üzerinden örneklem büyüklüğü hesabına gidilememiştir. Araştırma kapsamına alınacak bölgeler tarımda çalışmak üzere gelen işçi profilini olabildiğince doğru yansitacak şekilde, Kayseri Halk Sağlığı Müdürlüğü ile yapılan görüşmeler sonucunda belirlenmiştir. Bu belirlemede Toplum Sağlığı çalışanlarının tarım işçilerinin hareketliliği ve konaklaması ile ilgili tecrübelerinden yararlanılmıştır.

Çalışma sonunda hedeflenen nüfus üzerinden toplam 508 tarım işçisine ulaşıldı. Kayseri ve çevresine gelen tarım işçilerinin çalıştıkları alanlar, sayıları ve demografik özellikleri ile ilgili herhangi bir kayıt tutulmuyor olması ve sık yer değiştirdikleri için izlenmelerinin hiç kolay olmaması nedeniyle örneklem büyüklügünün tespit edildiği (\%10) toplam tarım işçisi popülasyonu bir önceki yıl gelenler hakkında Halk Sağlığı Müdürlüğü’ne bağl1 toplum sağlığ1 ekiplerince yapılan tespitlere dayanmaktadır. Araştırmanın yapıldığı bölge tarım işçilerinin en yoğun oldukları ve en uzun süre kaldıkları bölgeler olması sebebiyle hedeflenen sayıya ulaşılabilmesi açısından tercih edilmiş̧ir.

\section{Verilerin Toplanması}

Veri toplama aracı olarak anket formu ve doktor araştırıcı gözlemleri kullanılmıştır. Aile planlaması ile ilgili olarak da bu anket formunda yer alan sorular kullanılmıştır. 
Çalışmada ayrıca bu çalışmaya konu olmayan ağız diş sağlığı, lezyonları, sağlıklı yaşam biçimi davranışları ve psikososyal durum ile ilgili değerlendirmeler yapılması da planlanmıştır. Ayrıca tarım işçilerinin ne zaman çalışmak üzere gelecekleri ve bulundukları bölgede ne kadar süre kaldıkları konaklayacakları bilgisine tarım aracıları (Çavuşlar) vasıtasıyla da ulaşılmıştır. Bu ön çalışmadan sonra, hem Kayseri Halk Sağlı̆̆ı Müdürlüğü hem de tarım aracılarıyla kurulan sürekli iletişimler ile tarım işçilerinin geldiği zaman belirlenerek daha önce hazırlanan anket formları ile araştırma bölgelerine gidilmiştir. Araştırmanın yapıldığı bölgeler il merkezine yaklaşı $45 \mathrm{~km}$ uzaklıktaki tarım alanlarıydı ve işçilerin çalıştıkları tarlalardan dönüş saati akşam 18:0019:00 idi. Bu sebeple, bölgeye gitmek veri toplamak üzere öğle üzeri gidilip çalışma için tarlada olmayanlar ile ve daha sonra tarladan çalışma sonrası dönenler ile yüz yüze görüşülerek veri toplanmıştır. Veri toplama aracı olarak kadınların yaş, cinsiyet, medeni durum, öğrenim durumu vb. sosyodemografik özellikleri ile canlı doğum, ölü doğum, düşük, yaşayan çocuk sayısı gibi doğurganlık özelliklerini ve aile planlaması yöntemi kullanım durumlarını belirlemeye yönelik 45 soruluk anket formu kullanıldı. Veriler, araştırma ekibindeki 4 araştırmacı tarafından tarım işçilerinin çadır kurdukları bölgelerde yüz yüze görüşme yöntemiyle toplandı. Çalışmaya dahil edilen tarım işçilerini arasında 18 yaş üzeri eksik verisi olmayan Türkçe konuşan tüm kadınlar bu çalışmaya dahil edilmiştir ( $\mathrm{n}=141$ ).

\section{Araştırmanın Etik Boyutu}

Araştırma için Erciyes Üniversitesi Klinik Araştırmalar Etik Kurulu'ndan etik onay ve Kayseri Halk Sağlığı Müdürlüğü’nden kurum izni alınmıştır.

\section{Verilerin Değerlendirilmesi}

Bu çalışmada 141 evli kadına ait veriler değerlendirilmiştir. Elde edilen verilerin analizlerinde sayı ve yüzdelik dilimler kullanılmıştır.

\section{Araştırmanın Sınırlılıkları}

Araştırma, mevsimlik tarım işçileri üzerinde yapıldığı için elde edilen sonuçlar diğer tarım iş̧̧ilerine genellenemez. Sadece Kayseri merkezde üç ilçedeki mevsimlik tarım işçileri ile yapıldığı için elde edilen sonuçları tüm mevsimlik tarım işçilerine genellemek mümkün değildir. Ayrıca, toplam örneklemi tahmin zorluğu, Türkçe bilmeyen tarım işçilerinin olması, tarım işçilerinin hareketliliği nedeniyle hedeflenen örnekleme ulaşma zorluğu araştırmanın diğer sinırlılıklarındandır.

\section{BULGULAR}

Tablo1. Mevsimlik Tarım İşçisi Kadınların Sosyodemografik Özellikleri

\begin{tabular}{|l|l|c|c|}
\hline DEĞIŞKENLER & Sayı & \% \\
\hline \multirow{2}{*}{ Yaş Grupları } & $<18$ & 1 & 0.7 \\
\cline { 2 - 4 } & 18 ve üzeri & 140 & 99.3 \\
\hline \multirow{3}{*}{ Ŏğrenim Düzeyi } & Okuryazar değil & 98 & 69.5 \\
\cline { 2 - 4 } & Okuryazar & 26 & 18.4 \\
\cline { 2 - 4 } & İlkokul ve üzeri & 17 & 12.1 \\
\hline \multirow{2}{*}{ Sosyal Güvence } & Var & 122 & 86.5 \\
\cline { 2 - 4 } & Yok & 19 & 13.5 \\
\hline \multirow{3}{*}{ Yaşayan Çocuk Sayısı } & $<5$ & 46 & 42.6 \\
\cline { 2 - 4 } & $\geq 5$ & 95 & 57.4 \\
\hline \multirow{3}{*}{ Çalışma Süresi } & $<5$ yıl & 23 & 16.3 \\
\cline { 2 - 4 } & $5-9$ yıl & 28 & 19.9 \\
\cline { 2 - 4 } & 10 yıl ve üzeri & 90 & 63.8 \\
\hline \multirow{2}{*}{ Gelir Düzeyi * } & Yeterli & 4 & 2.8 \\
\cline { 2 - 4 } & Yetersiz & 99 & 70.2 \\
\hline Toplam & \multicolumn{2}{|l}{} \\
\hline
\end{tabular}

*38 kişi bu soruyu cevaplamamıştır.

Araştırma grubunun, yaş ortalaması 34.2 $\pm 12.1 \% 0.7$ 'si 18 yaş altında, $\% 69.5$ 'i okuryazar değil ve $\% 86.5$ 'inin sosyal bir güvencesi vardı. Kadınların \% 63.8'i tarım işçiliğinde 10 yıl ve daha fazla süredir çalışmakta olup \%70.2'si gelirini yetersiz bulduğunu ifade etmiştir.

Tablo2. Mevsimlik Tarım İşçisi Kadınların Doğurganlık İle İlgili Temel Özellikleri

\begin{tabular}{|l|l|c|c|}
\hline DEĞISSKENLER & Sayı & \% \\
\hline \multirow{3}{*}{ Evlenme Yaşı (n:126) } & $<15$ & 13 & 9.2 \\
\cline { 2 - 4 } & $15-20$ & 89 & 63.1 \\
\cline { 2 - 4 } & $>20$ & 24 & 17.0 \\
\hline \multirow{3}{*}{ İlk Gebelik Yaşı (n:114) } & $<15$ & 6 & 4.3 \\
\cline { 2 - 4 } & $15-20$ & 71 & 50.3 \\
\cline { 2 - 4 } & $>20$ & 37 & 26.2 \\
\hline \multirow{3}{*}{ İlk Doğum Yaşı (n:101) } & $<15$ & 3 & 2.1 \\
\cline { 2 - 4 } & $15-20$ & 64 & 45.3 \\
\cline { 2 - 4 } & $>20$ & 34 & 24.1 \\
\hline \multirow{2}{*}{ Canlı Doğum Sayısı (n:110) } & $<4$ & 41 & 37.3 \\
\cline { 2 - 4 } & $\geq 4$ & 69 & 62.7 \\
\hline \multirow{2}{*}{ Düşük Sayısı(n:87) } & Evet & 37 & 42.5 \\
\cline { 2 - 4 } & Hayır & 50 & 57.5 \\
\hline \multirow{2}{*}{ İki gebelik arasında geçen süre(n:74) } & $<2$ yıl & 64 & 86.5 \\
\cline { 2 - 4 } & $\geq 2$ y1l & 10 & 13.5 \\
\hline
\end{tabular}


Çalışmamızda, kadınların \%9.2'sinin ilk evlenme yaşı $<15, \% 63.1$ 'inin $15-20$ yaş arasında idi. Evli kadınların \% 50.3'ünün ilk gebelik yaş1 15-20 arasındaydı. İlk doğum yaşı $<15$ olanların oranı \%4.3 iken 15-20 yaş arasında olanların oranı \%45.3 idi. Canlı doğum sayısı 4 'ten fazla olan kadınların oranı ise \% 62.7 idi. En az bir kez düşük yapmış kadınların oranı $\% 42.5$ idi.

Yaşayan çocuk sayısı 5 ve 5 'ten fazla olanların oranı $\% 57.4$, ortalama sahip olunan çocuk sayısı $5.2 \pm 3.20$ olup, iki gebelik arasında geçen süre 2 yıldan az olan kadınların oran $1 \% 86.5$ idi.

Kadınların aile planlaması uygulamasına ilişkin davranışları değerlendirildiğinde; \%70.6'sının bugüne kadar hiç koruyucu yöntem kullanmadığı belirlenmiştir. Herhangi bir yöntem kullanıp da bu yöntemi birakan kadınların \%80.0'1 çeşitli yan etkilerinden dolayı yöntemi bıraktıklarını belirtmişlerdir.

Mevsimlik tarım işçisi kadınların aile planlaması yöntemi kullanmama nedenleri arasında \% 32.5'inin bilgi sahibi olmadığı için herhangi bir yöntem kullanmadığı, $\% 47,0$ 'ının ise eşleri istemediği için yöntem kullanmadığı tespit edilmiştir. Gebelikten koruyucu yöntem kullananların; \%61.8'i RİA, \%17.6's1 hap kullanmaktaydı. Çalışma kapsamında yapılan görüşme sırasında aile planlaması yöntemi kullanma durumu \% 73.7 iken; bunların \%42.3’ü rahim içi araç, \%30.8'u tüpligasyonu yöntemi ile gebelikten korunmaktaydi.

Kadınların \% 55.0'si kullanılan yöntemle ilgili bilgilendirildiğini ve yöntem hakkında bilgiyi \%38.9'u aile sağlığ1 elemanından, \%50.0'si ise diğer sağl1k

Tablo 3. Kadınların Aile Planlaması Yöntemi Kulanım Durumlarına İlişkin Özellikleri

\begin{tabular}{|c|c|c|c|}
\hline \multicolumn{2}{|l|}{ DEĞİŞKENLER } & \multirow{2}{*}{$\begin{array}{c}\text { Sayı } \\
37\end{array}$} & \multirow{2}{*}{$\begin{array}{c}\text { \% } \\
29.4\end{array}$} \\
\hline Bugüne kadar herhangi bir aile planlaması yöntemi kullanım & Evet & & \\
\hline durumu (n:126) & Hayır & 89 & 70.6 \\
\hline \multirow{4}{*}{ Aile planlaması yöntemi kullanmama nedeni (n:83) } & Çocuk istiyor & 39 & 47.0 \\
\hline & Bilgi sahibi değil & 27 & 32.5 \\
\hline & Eşi istemiyor & 12 & 14.5 \\
\hline & Diğer & 5 & 6.0 \\
\hline \multirow{4}{*}{ Bugüne kadar kullanılan aile planlaması yöntemi(n:34) } & RİA(Rahim İçi Araç) & 21 & 61.8 \\
\hline & Hap & 6 & 17.6 \\
\hline & Tüp ligasyon & 5 & 14.7 \\
\hline & Kondom & 2 & 5.9 \\
\hline \multirow{3}{*}{ Aile planlaması yöntemi bırakma sebebi (n:15) } & Yan etkisinden & 12 & 80.0 \\
\hline & Çocuk istiyor & 2 & 13.3 \\
\hline & Tüpligasyonu yaptırmış & 1 & 6.7 \\
\hline \multirow{2}{*}{ Şu anda aile planlaması yöntemi kullanma durumu(n:99) } & Evet & 26 & 26.3 \\
\hline & Hayır & 73 & 73.7 \\
\hline \multirow{5}{*}{ Şu anda kullanılan aile planlaması yöntemi (n:26) } & Ria & 11 & 42.3 \\
\hline & Tüpligasyon & 8 & 30.8 \\
\hline & Kondom & 4 & 15.4 \\
\hline & Hormonal enjeksiyon & 2 & 7.7 \\
\hline & Geri çekme & 1 & 3.8 \\
\hline \multirow{2}{*}{ Kullanılan yönteme ilişkin bilgilendirilme durumu(n:26) } & Evet & 15 & 57.7 \\
\hline & Hayır & 11 & 42.3 \\
\hline \multirow{3}{*}{ Yöntemle ilgili bilgiyi nereden/kimden alındığı (n:26) } & Aile hekimi & 2 & 7.7 \\
\hline & Aile sağlığg elemanı & 10 & 38.4 \\
\hline & Diğer sağlık kuruluşları & 14 & 53.9 \\
\hline \multirow{3}{*}{ Yöntemle ilgili sorun ile karşılaşıldığında başvurulan yer/kişi (n:26) } & Aile hekimi & 3 & 11.5 \\
\hline & Aile sağlığı elemanı & 9 & 34.6 \\
\hline & Diğer sağlık kuruluşları & 14 & 53.9 \\
\hline \multirow{3}{*}{ Kürtaj bir aile planlaması yöntemi midir?(n:84) } & Evet & 3 & 3.6 \\
\hline & Bilmiyorum & 12 & 14.3 \\
\hline & Hayır & 69 & 82.1 \\
\hline
\end{tabular}


kuruluşlarından aldığını belirtmiştir. Kullanılan yöntemle ilgili bir sorun yaşadıklarında \%38.1'i aile sağlığı elemanına ve \%52.4'ü diğer sağlık kuruluşlarına başvurmakta idi. Kadınların \%3.6'sı kürtajı bir aile planlaması yöntemi olarak görmektedir (Tablo 3).

\section{TARTIŞMA}

Bu çalışmada, MeTiK'ın doğurganlık özelliklerine ilişkin durumları ve aile planlaması yöntemi kullanım alışkanlıkları kesitsel bir biçimde yüz yüze görüşme yöntemiyle belirlenmiştir.

Araştırma grubunun yaş ortalaması $34.2 \pm 12.1$ olup, \%5.0'1 18 yaş altında idi. Kadınların \%69.5'i ise okuryazar değildi. Kadınların \% 50.3'ünün ilk gebelik yaşı 15-20 arasındaydı. Canlı doğum sayısı 4 'ten fazla olan kadınların oranı \% 62.7 idi. En az bir kez düşük yapmış kadınların oranı $\% 42.5$ iki gebelik arasında geçen süre 2 yıldan az olan kadınların oranı ise \%86.5 idi. Kadınların \%70.6'sının bugüne kadar hiç aile planlaması yöntemi kullanmadığ belirlendi.

Tarımsal işlerde çalışan kadınlarda üreme sağlı̆̆ sorunları kadını olduğu kadar doğacak bebeğini de etkilediğinden daha da önemli bir sorun olarak karşımıza çıkmaktadır $(9,11)$. Düşük sosyoekonomik düzey genç yaşta evlilik ve beraberinde getirdiği adölesan gebelikler, akraba evliliği, doğum öncesi bakım almamak ya da yetersiz almak vb. durumlar anne ve bebeğin sağlığını olumsuz yönde etkilemektedir $(9,10,13)$.

Araştırma grubumuzdaki kadınların \% 69.5'i okuryazar değildi. TÜİK 2015 rakamlarına göre genel toplumdaki 25 yaş ve üzeri nüfusta okuma yazma bilmeyen erkeklerin oran1 \%1.8 iken kadınlarda ise \%9.0'dır (14). Bu bulgu normal topluma göre okuma yazma bilmeme oranının mevsimlik tarım işçisi kadınlarda normal yerleşik topluma göre yaklaşık 7 kattan daha fazla olduğunu göstermektedir.

Kırsal kesimde erkeklerde altı yaş üzerinde eğitimi olmama/ilkokulu bitirmeme oran1 \%26.1; kadınlar arasında eğitimi olmama/ilkokul bitirmeme oranı \%47.6 olduğu (15), 15 yaş üzerindeki mevsimlik tarım işçisi nüfusun \% 31.4'ünün okuma yazma bilmediği, okuma-yazma bilmeme durumunun yaş ilerledikçe $\operatorname{arttığ~} 1,35$ yaş ve üzerinde yaklaşık iki kişiden birinin okuma-yazma bilmediği belirtilmektedir (16). Eğitimin, bireyin gerek yaşamını sürdürme ve kendini geliştirmesi gerekse içerisinde bulunduğu toplumla uyum içinde yaşama noktasında önemli bir payı vardır (17). Kadınların eğitim düzeyinin erkeklerin gerisinde kalması; sağlıklı bir toplum, dengeli ve tutarlı bir aile yapısı kurulması açısından olumsuz bir durum olarak değerlendirilmelidir (17). Türkiye'de, bütün çabalara rağmen, başta eğitim olmak üzere toplumsal cinsiyet eşitsizliği ve ayrımcıllı̆ı̆; eğitimden çalışma yaşamına, sağlıktan karar mekanizmalarına katılıma kadar yaşamın birçok alanında kadın ile ilgili eşitsizlikler söz konusudur (17-19). Bunların yanı sıra ana çocuk sağlığı açısından da genç yaşta evlenme, adölesan gebelikler, çok ve sık aralıklı gebelik ve doğum, tarım alanlarında doğum öncesi, sırası ve sonrası sağlık hizmetine erişememe gibi sorunlar da daha sık görülmektedir (9-12). Ayrıca tarım işçisi kadınların öğrenim düzeylerinin düşük olması da bu alanda çalışan kadınlar için anne ve çocuk sağlığı açısından riskleri artırabilmektedir.

Çalışmamızdaki kadınlarda ilk evlenme yaşı 15 ten küçük olanların oranı \%9.2, yaşı 15 ila 20 olan kadınların oranı ise \%63.1 idi. Evli kadınların yaklaşık yarısında (\%50.3) ilk gebelik yaşı 15 ile 20 arasındaydı. Yine kadınların \%45.3'ünün ilk doğum yaşı 15-20 yaş arasında ve canlı doğum sayısı 4 'ten fazla olan kadınların oranı ise $\% 62.7$ idi.

Türkiye Nüfus Ve Sağlık Araştırmaları (TNSA) 2013 verilerine her yaş grubunda, kırsal alanlardaki kadınların kentsel alanlardaki kadınlara göre daha fazla çocuk doğurduğu ve 15-19 yaş arasında doğurganlık oranının \%45.0, 25-29 yaştaki kadınların ortanca ilk doğum yaşının ise 22.3 olduğu belirtilmektedir (21). Yine TNSA 2013 sonuçlarına göre ilk gebelik yaşı 15-19 arasında olan kadınların oranı kentte \%1.2 iken kırda \%1.8 olduğu belirtilmektedir(21). Çalışmamızda evli kadınların yaklaşık yarısında (\%50.3) ilk gebelik yaşı 15 ile 20 olduğu belirlenmiştir.

Türkiye İstatistik Kurumu 2011 verilerine göre, yükseköğretim mezunu kadınların ortalama evlilik yaşının 25-29 yaş aralığında, ilk evliliklerini 16-19 yaş aralığında yapan kadınların ise herhangi bir okul bitirmeyen ya da ilköğretim mezunu olduğu ve öğrenim düzeyi yükseldikçe evlilik yaşının yükseldiği anlaşılmaktadır (17).

Türkiye İstatistik Kurumu 2015 verilerine göre, ilk evliliğini 2015 yılında yapmış olan kadınların ortalama evlenme yaş1 23.9'dur. (TÜIKK 2015) (20). TNSA 2013 de ise Türkiye'de 25-49 yaş grubundaki kadınlar için ilk evlenme yaşı 21 ve erken yaşta yapılan evliliklerde, 15-19 yaş grubundaki kadınların \%7'sinin evlendiği belirlenmiştir (TNSA 2013) (21). Bulgular aynı zamanda eğitim düzeyine göre değerlendirildiğinde 25-49 yaşlar arasındaki kadınlar içinde, hiç eğitimi olmayan kadınlar ile en az lise mezunu 
kadınlar arasında ilk evlenme yaşında lise mezunları lehine yaklaşık altı yıllık bir fark bulunmaktadır.

Mevsimlik tarım işçileri ile yapılan bir çalışmaya göre bebek ve anne ölümlerinin diğer gruplara göre üç kat fazla, ölü doğum ve düşük oranlarının da daha yüksek olduğu belirtilmektedir (13). Mevsimlik tarım işçilerinin yaşam koşullarının belirlendiği bir başka çalışmada ise, üreme sağllğı sorunları, eğitim ve sağlık hizmetlerine erişememe nedeniyle erken ölüm ve hastalıklara maruziyetlerinin daha sık olduğu belirlenmiştir (2).

Araştırmamızda, kadınların \%70.6'sı bugüne kadar hiç koruyucu yöntem kullanmadığını belirtti. Kadınların $\% 32.5$ 'i bilgi sahibi olmadığı için, \%47.0'1 ise eşleri istemediği için aile planlaması yöntemi kullanmıyordu. Bugüne kadar kullanılan yöntemlerde ilk üç sırayı RİA (\% 61.8), hap (\%17.6) ve tüp ligasyonu (\%14.7) almaktaydı.

Literatürde, 15-49 yaş evli kadınlarda herhangi bir kontraseptif yöntem kullanma \%73.5, herhangi bir modern yöntem kullanma \%47.4 ve herhangi bir geleneksel yöntem kullanma oranının \%26.0 olduğu bildirilmektedir (21). TNSA 2013 verilerine göre 15-49 yaş evli kadınların \%16.8'i RİA, \% 15.8'i kondom kullandığı ve \%9.4'ü tüpligasyonu yaptırmışıtır (21).

Çalışmamızda kadınların sahip oldukları ortalama çocuk sayıs1 5.2 ve en az bir kez düşük yapanların oranı ise $\% 42.5$ idi.

Türkiye'de 15-49 yaş evli kadınların ortalama sahip oldukları çocuk sayısının 2.23 iken (21) MeTiK'lerde 4.5 olduğu belirtilmektedir (22). Yine literatürde MeTIK'lerde ortalama çocuk sayısının 4.3 ile 6.8 arasında değiştiği (16), yaklaşık her üç kadından birinin düşük yaptığı, düşük ve ölü doğum yapmanın beş ve üzerinde gebelik yaşayanlarda ve mevsimlik tarım işçisi olanlarda daha fazla olduğu belirtilmektedir (11). Dolayısıyla bu gruptaki kadınların genel topluma göre doğurganlığın daha fazla olması; düşük, ölü doğum, erken doğum gibi riskli durumlar açısından daha fazla risk altında olduklarını göstermektedir.

\section{SONUÇ}

Tarım işçileri arasında bulunan kadınlarda genel topluma göre ilk gebelik yaşı düşük, doğum sayısı fazla ve gebelik aralıkları bir yıldan az bir süredir. Zor yaşam şartları ve çalışan nüfusun olabildiğince fazla olmasının aile yaşamına getireceği katkı nedeniyle erken çocuk sahibi olma, çok sayıda gebe kalma ve doğum kontrol yöntemlerini oldukça kısıtlı düzeyde kullanma olduğu sonucuna varılmıştır.
Ayrıca etkili doğum kontrol yöntemleri hakkında yeterince bilgi sahibi olmamaları da yüksek doğum oranına katkı sağlamış olabilir. Ayrıca düşük eğitim seviyesi, erken yaşta çocuk sahibi olma, çok ve sık doğum yapma, aile planlaması yöntemlerinin kısıtlı düzeyde kullanılması gibi sorunlar kadın sağlığını olumsuz yönde etkilemektedir.

\section{ÖNERILLER}

Mevsimlik tarım işçisi kadınların, genç nüfusa sahip olması üreme sağlığı hizmetlerine öncelik verilmesi gerektiğini açıkça göstermektedir. Bu sebeple kadınlara yönelik sunulan sağlık hizmetleri bu gruplar açısından daha önemli hale gelmektedir. Buna göre organizasyon ve hizmet sunumu planlaması yapılmalıdır.

- Araştırmanın kapsamının genişletilerek diğer tüm tarım işçilerinde de yapılması,

- Ekonomiye önemli katkıda bulunan bu grubun gereksinimlerinin tespit edilerek üreme sağlığı ve aile planlaması konuları hakkında farkındalık düzeylerinin arttırılması için eğitim programları planlanması,

- Bu konuya özgün çalışmaların yapılması önerilir.

\section{KAYNAKLAR}

1. Kaya M, Özgülnar N. Mevsimlik (Gezici/Geçici) Tarım İşçilerinin İki Yerleşim Birimindeki Yaşam Koşulları ve Sağlık Durumlarına Niteliksel Bakış. Turk J Public Health 2015;13(2): 115-126.

2. Fereli S, Aktaç Ş, Güneş FE. Mevsimlik Tarım İşçilerinin Çalışma Koşulları, Beslenme Durumları ve Görülen Sorunları. Gazi Üniversitesi Sağlı Bilimleri Dergisi 2016;1(3): 36-47.

3. http://www.tuik.gov.tr/PreHaberBultenleri. do?id=18645[Erişim tarihi: 20.09.2016].

4. Jadhav R, Achutan C, Haynatzki G, Rajaram S, Rautiainen R. Review and Meta-analysis of Emerging Risk Factors for Agricultural Injury. Journal of Agromedicine 2016; 21(3): 284-297.

5. Karaman K, Yılmaz AS. Mevsimlik Tarım İşçileri Ve Enformel İlişkiler Ağı: Giresun'da Çalıșan Mevsimlik Tarım İşçileri Üzerine Bir Araştırma. ZfWT 2011; 3(1):211-226.

6. Selek Öz C, Bulut E. Mevsimlik Tarım İşçilerinin Türk Hukuk Sistemi İçerisindeki Yeri. Çalışma Dünyası Dergisi 2013; 1 (1): 94-111.

7. Koruk İ. İhmal Edilen Bir Grup: Göçebe Mevsimlik Tarım İşçileri. Mesleki Sağlık ve Güvenlik Dergisi 2010;10(38): 18-21.

8. Selek Öz C, Bulut E. Düzgün İş Bağlamında Mevsimlik Gezici Tarım İşçilerinin Çalışma Koşullarının Değerlendirilmesine 
Yönelik Bir Alan Araştırması. Bilgi Dergisi 2014; 28: 99121.

9. https://www.tbmm.gov.tr/sirasayi/donem24/yil01/ss.716. pdf[Erişimtarihi: 15.09.2017]

10. Hayata Destek Derneği Mevsimlik Gezici Tarım İşçiliği Araştırma Raporu, 2014.

11. Şimşek Z. GAP Tarımda Çalışanların Sağlığı Araştırması Raporu. Şanlıurfa: Harran Üniversitesi Tarımda İş Sağlığı ve Güvenliği Uygulama ve Araştırma Merkezi, 2013.

12. Özbekmezci Ş, Sahil S. Mevsimlik Tarım İşçilerinin Sosyal, Ekonomik ve Barınma Sorunlarının Analizi. Gazi Üniversitesi Mühendislik Mimarlık Fakültesi Dergisi 2004; 19(3): 261-274

13. http://www.mevsimliktarimiscileri.com/ files/dosya/1_3_635375888071845188.pdf [Erişim tarihi:10.09.2017].

14. http://www.tuik.gov.tr/PreHaberBultenleri.do?id=24643: [Erişim tarihi:01.09.2017].

15. Tarım Çalışanlarının Sosyodemografik Özellikleri Ve Risk Altındaki Gruplar. I. Tarım Sağlığı ve İş Güvenliği
Sempozyumu Kitabı,6-7 Nisan Harran Üniversitesi 2012; 27-33.

16. Çelik K, Şimşek Z, Yüce Tar Y, Kırca Duman A. Gezici Mevsimlik Tarım İşinde Çalışan Kadınların Çalışma ve Yaşam Koşullarının İrdelenmesi. The World Bank,2013;5-23.

17. Özaydınlık K. Toplumsal Cinsiyet Temelinde Türkiye'de Kadın Ve Eğitim. Sosyal Politika Çalışmaları Dergisi 2014; 33: 93-112.

18. Arat N. Kadınların İnsan Hakları. Kadın Araştırmaları Dergisi 1999; 5: 5-10.

19. Seven MA, Engin AO. Türkiye'de Kadın Eğitimi Alanındaki Eşitsizlikler. Atatürk Üniversitesi Sosyal Bilimler Enstitüsü Dergisi 2007; 1(9):177-188.

20. http://www.tuik.gov.tr/PreHaberBultenleri.do?id=21519 [Erişim tarihi: 25.01.2016].

21. http://www.hips.hacettepe.edu.tr/tnsa2013/rapor/ TNSA_2013_ana_rapor.pdf[Erişim tarihi: 15.01.2016].

22. Görücü İ, Akbıyık N. "Türkiye'de Mevsimlik Tarım İşçiliği: Sorunları Ve Çözüm Önerileri. Hikmet Yurdu Düşünce Yorum Sosyal Bilimler Araştırma Dergisi 2010; 3(5):189219 . 